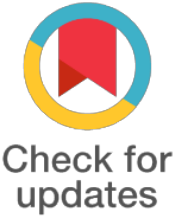

${ }^{*}$ For correspondence:

mushtaq.hussain@duhs.edu.pk

Competing interests: The authors declare that no competing interests exist.

Received: 2017-06-15

Accepted: 2017-08-13

Published: 2017-09-05

Copyright The Author(s) 2017. This article is published with open access by BioMedPress (BMP).

This article is distributed under the terms of the Creative Commons Attribution License (CC-BY 4.0) which permits any use, distribution, and reproduction in any medium, provided the original author(s) and the source are credited.

\section{Investigating Molecular Interactions of EBV Oncogene, EBNA1, by Heterologous Cloning and Peptide Array System}

\author{
Mushtaq Hussain ${ }^{1}$, Joanna B Wilson² \\ 1. Bioinformatics and Molecular Medicine Laboratory, Dow International Medical College Dow \\ University of Health Sciences, Ojha Campus, Pakistan \\ 2. Institute of Cell, Molecular and Systems Biology, University of Glasgow
}

\section{Abstract}

Background: $E B N A 1$ is an important latent genes that is involved in the oncogenesis associated with Epstein Barr Virus. The protein is highly promiscuous in terms of its interaction with the several proteins including $\mathrm{EBP}_{2}$ and $\mathrm{USP}_{7}$, a $\mathrm{p}_{53}$ stabilizer. Herein, we aim to investigate the interactions points of molecular complexes of EBNA1, an EBV oncogene, in order to design potential therapeutic peptides.

Methods: Full length $\mathrm{EBNA}_{1}, \mathrm{EBP}_{2}$ and $\mathrm{USP}_{7}$ models were constructed employing iterative threading. After proper refinements of models, EBNA1 dimer was constructed employing geometrical and structural constraints. Disruptor peptide was designed and its efficiency was assessed by molecular docking and confocal microscopy. In parallel, USP7 and EBP 2 molecules were expressed in $\mathrm{pET} 28 \mathrm{c}$ expression vector and after purification by affinity chromatography, the purified proteins were probed over EBNA1 peptide array (wild type and alanine substitution array) to resolve the fine interaction details. Finally, structural conformations of intermolecular complexes were examined by molecular docking.

Results: EBNA1 forms a dimer by engaging its C-terminal DNA binding domain where a proline loop of one molecule penetrated the C-terminal tail of another monomer. A disruptor peptide designed accordingly tend to bind in that region and found to inhibit EBNA1 dimerization resulting in the cellular apoptosis as observed in confocal microscopy and MTT assay. Peptide array systems showed the binding EBNA1 at the glycine and arginine rich regions especially ranging between 325 to 375 amino acids. Similarly, USP7 interactions were noticed between 441 to 450 amino acids where Ser 447 holds a key position. Interestingly, phosphorylation of this serine completely inhibits the interaction. Molecular docking analysis further verify the binding sites and their draggability.

Conclusion: The present data shows molecular interactions of EBNA1 molecules at molecular resolution. The findings can be exploited to design inhibitors to curtail molecular interactions that leads to pathological consequences.

\section{Keywords}

EBV, EBNA1, USP7, EBP2, Cancer 


\section{Funding}

Higher Education Commission, Govt of Pakistan

\section{References}

Hussain, M., Gatherer, D., \& Wilson, J. B. (2014). Modelling the structure of full-length EpsteinBarr virus nuclear antigen 1. Virus genes, 49(3), 358-372. 